\title{
When a seawall is visible: Infrastructure and obstruction in post-tsunami reconstruction in Japan
}

\author{
Shuhei Kimura
}

Faculty of Humanities and Social Sciences, the University of Tsukuba

1-1-1 Tennoh-dai, Tsukuba City, Ibaraki Prefecture, Japan 305-8571

shuhei.kimura@gmail.com

\begin{abstract}
The triple disaster of March 11, 2011 posed a formidable challenge for Japanese society in general, and for affected coastal communities in particular. In the immediate aftermath of the catastrophe, there was widespread support for the construction of high seawalls to protect communities. However, many communities began questioning this approach. In Maehama, the question of land-reconstruction and protection gave rise to a set of complex responses. The government aimed to put in place even higher seawalls; however, the local community proposed instead to mark the boundary of high water with trees and stakes. These solutions instantiate different ways of infrastructuring the post-tsunami environment for safety, and they carry different assumptions about infrastructure itself. Whereas the seawall solution was technical and quantitative, centering on the question of height, the boundary markers embedded a qualitatively different set of assumptions about what makes a workable infrastructure. In particular this difference centered on issue of visibility. On the one hand, the seawall was meant to slowly become unremarkable, whereas the boundary markers were specifically intended to maintain community memory. On the other hand, the seawall would make the sea itself invisible, whereas keeping the sea in sight is very important to villagers. However, the opposition between these forms of infrastructuring the environment was not total. Slowly, a solution was negotiated in which the sea wall and the boundary markers could complement one another. This situation highlights the intricate and transformable relation between visible and invisible forms of infrastructure.
\end{abstract}

\section{Keywords}

Disaster, Infrastructure, Invisibility, Japan, Visibility

\section{Biographical note on the author}

Shuhei Kimura is assistant professor of cultural anthropology at the University of Tsukuba, Japan. Since 2011 he has conducted field research in tsunami-stricken communities in northeastern Japan and published several research articles on disaster and public anthropology. 


\section{When a seawall is visible: Infrastructure and obstruction in post-tsunami reconstruction in Japan}

\section{Acknowledgements}

I would like to thanks the anonymous reviewers, Casper Bruun Jansen and Atsuro Morita as well as the guest editors, Anders Blok, Brit Ross Winthereik and Moe Nakazora, for their very helpful comments on previous drafts. This work was supported by the Japan Society for the Promotion of Science (Grants-in-Aid for Scientific Research 23401042, 25770310, and 26282113), the Toyota Foundation (D12-E2-0061), and the International Research Institute of Disaster Science, Tohoku University (B-21, 2012).

\section{Introduction}

I met Konno-san, a stocky, gray-haired man in his early fifties, in his home village of Maehama $^{1}$ on the coast of Iwate Prefecture ${ }^{2}$. As we were talking over drinks in his temporary housing late one night in autumn 2012, Konno-san told me that his wife's death in the tsunami of March 11, 2011 was 'embarrassing.' It was the first time he had spoken to me explicitly about her death, and his choice of words astonished me. He then dismissed the idea that his wife's name should be inscribed in the village tsunami memorial, which was then being planned. 'Only 30 people died out of 2,500 inhabitants.... She was not old like the other victims. Since Maehama has suffered from tsunamis repeatedly, the people living here should know to expect a tsunami after every big quake. Furthermore, the tsunami of March 11 hit the village more than 30 minutes after the quake was felt. I can't bear to think about the neighbors gossiping about her death.'

1 Personal names and the village name have been changed. Administratively, the village referred to here as Maehama is a part of Öfunato City, Iwate Prefecture. My first visit to Öfunato was just one year before the tsunami (Kimura, 2014). I started field research on the disaster there two months after the tsunami. During the first year after the tsunami, I traveled there regularly and conducted interviews with survivors, public officials, and volunteers. Since the beginning of 2012, two urban planning colleagues of mine, Hirotaka Ikeda and Shin Aiba, and I have supported reconstruction efforts in Maehama including drafting local reconstruction plans (Kimura, 2015).

2 The prefectures most severely affected by the disaster of March 11 were Iwate, Miyagi, Fukushima, and Ibaraki. Since Iwate, Miyagi, and Fukushima are geographically included in the Tohoku region, 'Tohoku' is often used as a synonym for the entire area affected by the disaster. 
Konno-san believed that his wife had both had sufficient warning and ability to evacuate, yet she had failed to do so. So why did his wife underestimate the tsunami? We can no longer hear the story from her lips. Maybe it was because she was not a native of the village (she was born and raised in Tokyo). Perhaps the false tsunami warning that happened a few days prior to the disaster led her to misjudge the threat. According to Konno-san and other locals, however, the eight-meter seawall enclosing the cove of Maehama was undoubtedly a crucial factor in her decision. Konno-san speculated that his wife had stayed home because she believed the seawall would protect her. In other words, the existence of the seawall suggested to her that experts were confident that no tsunami would rise above it.

The triple or 'four-fold' (Takahashi, 2011) disaster of March 11, 2011 inflicted devastating damage on Japan. At 2:46 PM, a mega-earthquake of 9.0 magnitude occurred off the northeastern coast of Honshu Island. This earthquake triggered the aforementioned massive tsunami, which in turn caused a severe accident at the Fukushima nuclear power plant. According to the Japanese Police Agency, the disaster killed more than 15,000 people directly and approximately 3,000 more indirectly. ${ }^{3}$ The Cabinet Office of Japan estimates the financial toll at about 17 trillion Japanese yen, making it the most costly disaster ever. Borrowing Numazaki Ichiro's words (2012), the disaster was, and still is, 'too wide, too big, too complicated to comprehend.'

Although the number of casualties was far smaller than those associated with other catastrophic disasters such as the Indian Ocean Tsunami of 2004 or the Haiti Earthquake of 2010 , it posed a formidable challenge to Japanese society. Even now, some four years after the disaster, approximately 250,000 people are still evacuated or displaced. The process of recovery has been slow, and it is quite uncertain when, or if, things will get back to normal. This is not only because of the massive scale of damage, including the nuclear accident, but also because of the economic decline that has plagued Japan since the 1990s. Furthermore, the large-scale restructuring and integration of local governmental institutions conducted over the last two decades has disempowered local communities. Given the historical dependence of local economies on the government, ${ }^{4}$ it is very difficult for them to escape

${ }^{3}$ Statistically death caused by strained living environment in shelters, mental stress, or other indirect reason caused by the disaster is categorized as 'shinsai kanren shi' (disasterrelated death).

${ }^{4}$ Some historians underline that Japan's modernization has required continued sacrifice in the Tohoku region. For example, Akasaka et al. (2011) argue that Tohoku has been a virtual internal colony in Japan, assuming a role of the main source of labor, crop, and energy (including electricity from nuclear power plants) for Japan's economic growth. Since the 1960s, the central government has attempted to improve the situation through 
this situation by themselves.

Considering the vulnerability of local communities, Konno-san's story is at once evocative and ironic. Whether his wife underestimated the force of nature or was overconfident in the public systems in place for disaster prevention, her mistake was proved only as she was swallowed by the tsunami. In any case, it is important to note that her expectations were apparently based, consciously or unconsciously, on what Anthony Giddens (1991) calls 'the expert system' embedded in the seawall. In this sense, her personal story exemplifies that the disaster was experienced as 'soutei-gai' (beyond expectation). As an expression of surprise, soutei-gai became a buzzword used to characterize the triple disaster after high-level bureaucrats and spokespersons for TEPCO (Tokyo Electronic Company) repeatedly used it on television to deny responsibility for the disaster. Later, through studying the evidence and the spokespersons' statements, citizens concluded that the company's expectations had been unreasonably optimistic. The company had knowingly collected data only on 'reasonably expectable and manageable' events and refrained from taking into account data on 'unlikely' events (cf. Morita, Blok, and Kimura, 2013). Manipulating their own expectations in this way, the company had ensured that many future events could be categorized simply as soutei-gai -- beyond expectations.

From deciding on the height of the seawall to determining building standards for nuclear power plants and the locations of public shelters, ${ }^{5}$ official (un)expectations were thus embedded in the existing public safety infrastructure. Not surprisingly, therefore, the discrepancy between these expectations and the reality of the tsunami resulted in many instances of soutei-gai. At the same time, due to outwards appearance of invulnerability meant elements of the public safety infrastructure, such as the seawall, promoted a sense of security. This permitted residents to adopt, consciously or unconsciously, an attitude of complacency or carelessness (cf. Sayre, 2011).

The survivors' reactions to the government-led reconstruction projects after the 2011 tsunami have been ambivalent and complicated. In the immediate aftermath of the tsunami, many people embraced the government's plan to raise the height of the seawalls even further to protect their communities from the next great tsunami. As things slowly began returning

the Comprehensive National Development Plans, but these plans had the counterproductive outcome of reinforcing the dependency of local communities on governmental subsidy and public works projects such as large-scale construction of transportation infrastructure.

5 In accordance with the law, each municipality had designated a public shelter for emergencies in each neighborhood in advance. However, the 'unexpectedly' high water levels associated with the tsunami of March 11 submerged several shelters and killed the evacuees. 
to 'normal,' however, people also increasingly began questioning this strategy. Some doubted whether higher seawalls are indeed worth the enormous amount of time, money and construction materials required by the project. Others worry that higher seawalls will make coastal residents less aware of the risk of future tsunamis, the consequences of which will be defined simply as soutei-gai.

Different values and visions regarding the reconstruction of disaster management facilities have emerged in the course of these discussions. While some demand that new forms of safety infrastructure are installed as soon as possible, others are in favor of a longer process of planning. Whereas the government intends to build uniform seawalls in every affected community, based on scientific considerations alone, other voices urge that the unique landscapes and community conditions should be taken into account in determining socially acceptable designs. Still others recommend that the new public infrastructure should not take the form of seawalls at all, but instead center on making public reminders of impact on the tsunami on the locality.

This situation corresponds perfectly with Susan Leigh Star's famous definition of infrastructure as that which 'becomes visible upon breakdown' (Star and Ruhleder, 1996). The seawalls formerly in place were literally broken down, and the concept of seawalls is now on the table with its black box open (in Latour's sense). But what would be a good outcome of this tragic story? Is it preferable, as government officials hope, to close anew the black box of safety infrastructure, making the seawall unnoticed and the seawall unremarkable? Or is a better alternative found in local responses focusing on developing a safety infrastructure that will remain visible testimony to historical events and future dangers? Exploring these ongoing discussions concerning seawalls and safety infrastructures after the tsunami, I argue that they offer a fresh vantage point for considering what constitutes a good safety infrastructure. As I show, these discussions center not only on the technical specifications of seawalls, but also, critically, on the location and forms of visibility and invisibility these walls are given within local communities and landscapes. If these qualitative dimensions of infrastructure development are taken into account it may be possible to overcome the binary choice between invisible and visible infrastructure.

\section{Safety, infrastructure, visibility}

The controversy over the reconstruction of public safety infrastructure after the tsunami is located at the intersection of two forms of inquiry: the study of safety and of infrastructure.

As Michel Foucault (2009) pointed out, safety is one of the key concepts of modern governmentality. As statistics and the concept of risk were established in $18^{\text {th }}$ and $19^{\text {th }}$ Century France, new governmental technologies also emerged, centering on the question of 
how to manage the environment in a way that would promote harmonious relations between people and things. Anthropologists of biosecurity have followed his seminal work in recent explorations of contemporary approaches to the 'defense' of society. Andrew Lakoff (2008), for example, characterizes large-scale computer of the spread of infectious disease as a 'vital system' for an emerging mode of governmentality. Its particular rationality, he argues, centers on generating a perpetual state of preparedness rather than aiming for prevention. In a related vein, Limor Samimian-Darash (2009) has analysed the Israeli biosecurity system as based on a 'pre-event configuration,' which enables the government to recognize, diagnose, and respond to unforeseen threats.

In addition, Stavrianakis et al. (2011, 1; see also Collier and Lakoff, 2008) note that 'the rise of new security frameworks within government apparatuses are increasingly [directed] to "low-probability/high-consequence" events rather than civil defense and allhazards planning.' Yet given the impossibility of predicting all hazardous events, how is it possible to implement a comprehensive approach for mitigating risk? According to Stavrianakis et al., this 'vital system' focuses on capacity building. By indirectly cultivating citizens' capacity to prepare for critical events (cf. Deleuze, 1992), this is an approach that aims to mobilize citizens to become cogs in the governmental system. This theoretical framework provides one perspective through which we can examine the Japanese government's system of natural disaster management. Compared to the sophistication of the biosecurity system of the United States, the former may look poorly organized and out of date. Nevertheless, it, too, emphasizes non-structural human elements alongside structural measurements. Moreover, it, too, gains legitimation based on statistical calculation.

As a complex aggregate of technologies for managing the circulation of human and nonhuman agents, infrastructure is important for governmental aspirations to control citizens' conduct. According to one recent definition, infrastructure 'facilitate[s] the flow of goods, people, or ideas and allows for their exchange over space' (Larkin 2013, 328). Under the influence of Marxist theory, which characterizes infrastructure as the material and technical base upon which social action rests, scholars in the tradition of STS (science and technology studies) have examined how social interactions are conditioned and (re)produced by the invisible base of infrastructure. Since social interaction in turn shape infrastructure, this is a dialectical position focusing on the mutual shaping of infrastructures and subjects.

Along these lines, Leigh Star and Geoffrey Bowker, argued for the importance of seeing infrastructure not as a determined stage, but rather as a network of elements gradually assembled, maintained, or abandoned (Star and Ruhleder, 1996; Star 1999; Bowker and Star, 1999; also Edwards et al., 2009). Related ANT-inspired approached, which have flourished in STS and anthropology, have examined the relation between social interaction, local 
political ecology and infrastructures such as water and sewage systems (Anand, 2011; Jensen, 2014), roads (Thévenot, 2002; Dalakoglou, 2010), and informal communication infrastructures (e.g. Elyachar, 2010).

Some anthropologists of infrastructure have critically reexamined Star's claim that infrastructure becomes 'visible upon breakdown' (see Larkin 2013). Their key observation is that infrastructure can take on different meanings and thus different visibilities for different people, at different times, and in different places. For example, a large-scale piece of infrastructure may be treated as a monument. Or the act of breaking ground for a new highway or launching a satellite may be defined as a national project. Meanwhile, a regional information hub can be the target of terrorism, and a waste-disposal facility can be seen as a nuisance to comfortable community life. To put it simply, infrastructure is not always infrastructure only in a material sense: it can have many other symbolic or imaginative capacities. In consequence there is no simple binary between the visibility and invisibility of infrastructure. What is visible or invisible changes depending on viewpoint, it varies over time, and it is subject to negotiation.

The demands for new seawalls made by survivors of the tsunami are worth reexamining in this light. Because of the generally massive shape of seawalls, diverse concerns over their design tend to be reduced to the one-dimensional issue of wall height. Yet, the recent work on the anthropology of infrastructure just mentioned, suggests the importance of examining the issue of visibility and invisibility with more care and attention. How, indeed, are seawalls supposed to function? What kinds of visibility or invisibility are they meant to engender, and for whom? What actions or inactions are they presumed to facilitate?

The Japanese mass media has repeatedly reported about local worries that high seawalls would interfere with their view of the sea, thus changing the very landscape of the affected communities. In fact, 'our vision of the sea will be obstructed' is the most widespread expression of the affected communities' anxiety about the proposed seawalls. Locals are adamant that, without a view of the sea, it will be hard for fishermen to continue their usual practice of watching the 'face' of the sea. Indeed, according to the folklorist Kawashima Shuichi (2012), who has explored the traditional knowledge and practices of local fishermen, having a view of the sea is a crucial element for making a successful catch. Local fishermen start their days by watching 'unadura' (the 'face' of the sea). Based on the signs they perceive in the color of the sea, the state of the waves, the feel of the clouds and the direction of the wind, they make daily decisions on fishing strategies. They also determine where they are ('yama ate') by observing landmarks on the shore (e.g. mountain peaks, capes, or tall buildings). In this manner, their knowledge of fishery is inseparable from their vision of the landscape. 
Moreover, if the sea is rendered invisible it will be difficult for people to decide whether they should evacuate in the case of future emergencies. This, too, is related to local practices, including a heterogeneous collection of local sayings, behavior patterns, and social arrangements, called 'saigai-bunka' (disaster culture) by the social scientists who have explored it. As time goes by, or if the landscape changes, as it would do dramatically with the introduction of giant seawalls, there is a significant risk that such saigai-bunka will cease working effectively. Of course, as Konno-san's tragic story suggest, disaster culture is not necessarily sufficient to prevent disaster.

Even so, what these observations indicate is that the completion of new large seawalls may well increase the risk to public safety, in the manner suggested by soutei-gai stories suggest, since the walls would slowly blind residents to the dangers of the sea.

It is also not obvious that a lower seawall would be preferable. Indeed, what the local people want seems inconsistent: they want both a safer built environment and preserving visible awareness of the danger of natural disasters. This poses the question of whether there is any way to avoid the sentiment expressed in the Japanese saying that Natural disasters strike when we forget about them'? In other words, is it possible to feel safer without for that matter becoming less attentive to the remaining risk of catastrophe?

What is at stake here is the question of how people sort out the entangled and antagonistic relations between diverse forms of visibility and invisibility, between infrastructure and obstruction, between past experience and future plans, and between daily life and emergencies, in the context of a changing landscape.

Taking it a step further, it appears to me that what people seek is a visible and public safety infrastructure. Below, I describe some local attempt to achieve this infrastructure, by attending to at once to the experience of past tsunamis and to the anticipation of future tsunamis.

\section{From evacuation to protection}

Major natural disasters often lead to the reform of disaster management systems. The Disaster Basic Law, which specifies today's general framework for disaster management in Japan, was legislated in 1961 after a typhoon had killed more than 5,000 people two years previously. The law stated that natural disasters should primarily be tackled by the local municipalities with support from the central and prefectural governments, and in cooperation with local residents. ${ }^{6}$ During this period, the engineering approach to disaster management, including the construction of concrete riverbanks and seawalls, became

\footnotetext{
${ }^{6}$ Roughly speaking, Japan's administrative structure is three-layered, consisting of the central government, prefectural governments, and local municipalities.
} 
dominant, at least in the public discourse. ${ }^{7}$ In the following, I discuss three major tsunamis (1933, 1960, and 2011) each of which affected the local public safety infrastructure of the Pacific coast communities of northeastern Japan.

As Konno-san recalled, a major tsunami can be expected to hit this area once every several decades. Statistically speaking, therefore, every inhabitant of this area is expected to experience a tsunami once or twice in his or her life. In spite of these disasters, people continue to live along the seashore, taking advantage of the abundant natural resources. To cope with the risk, they maintain traditions including the telling of stories that convey the collective memory of previous tsunamis. Thus, when the ground trembled violently in the middle of a winter night in 1933, older residents rushed the younger villagers to higher ground. They do so because they remembered the Meiji Sanriku Tsunami of 1896, which had killed about 22,000 people ${ }^{8}$ and destroyed 12,000 homes. As a result, although the 1933 tsunami destroyed thousands of houses and devastated the area, the death toll was much lower than in $1896 .{ }^{9}$

The official report by Iwate Prefecture (Iwate-ken Doboku-ka, 1935) described the damage in detail. One section outlines the effect on a hamlet of Maehama: 'All the houses near the shoreline were washed away. The tsunami intruded deep [into the hamlet] along the course of the small river. Only the big houses in the back remain standing without changes in appearance. [Local people] affirmed that tsunami height was about 8 meters by eye.'

After the 1933 tsunami, the central government did not leave the recovery process in the hands of local people. During this time, Japan was going to war in East Asia, and the government wished to create a strong sense of national power. Based on the advice of Imamura Aritsune, the leading seismologist of the time, the government promoted collective relocation to higher ground in the devastated areas. People who had lost their houses in the tsunami readily accepted this idea. With the aid of government funding, the residents of the affected communities prepared the slopes of nearby hills and mountains for housing. As a result, approximately 2,200 houses in 28 communities in Iwate Prefecture were rebuilt on higher ground within the next several years. This government-led relocation project effectively transformed the spatial layout of the coastal communities. Maehama was

\footnotetext{
7 The so-called Kobe Earthquake of 1995 set public discourse on a new track, as the mutual assistance provided by residents of the affected area and the volunteer work offered by citizens from neighboring areas highlighted the insufficiency of the local municipalities' capacity to deal with either the emergency or the subsequent long-term recovery process.

8 Maehama lost half of its population of 2,500 to the tsunami in 1896.

${ }^{9}$ It is estimated that the Showa Sanriku tsunami in 1933 killed about 3,000 people and destroyed 11,000 houses.
} 
considered one of the most successful cases since almost all of the 200 destroyed houses were rebuilt in its four so-called 'fukkouchi.'

In addition, Asahi Shimbun, one of Japan's major newspaper companies, used donated funds to raise stone monuments commemorating the tsunami in the affected communities. These monuments bore inscriptions such as 'Watch for tsunami after every big quake,' and 'Don't build a house lower than this point.' In this way, not only did the fukkouchis and the monuments become part of the local landscapes of the affected communities, they also became material and symbolic means of increasing tsunami awareness and of reminding people to evacuate to safe areas.

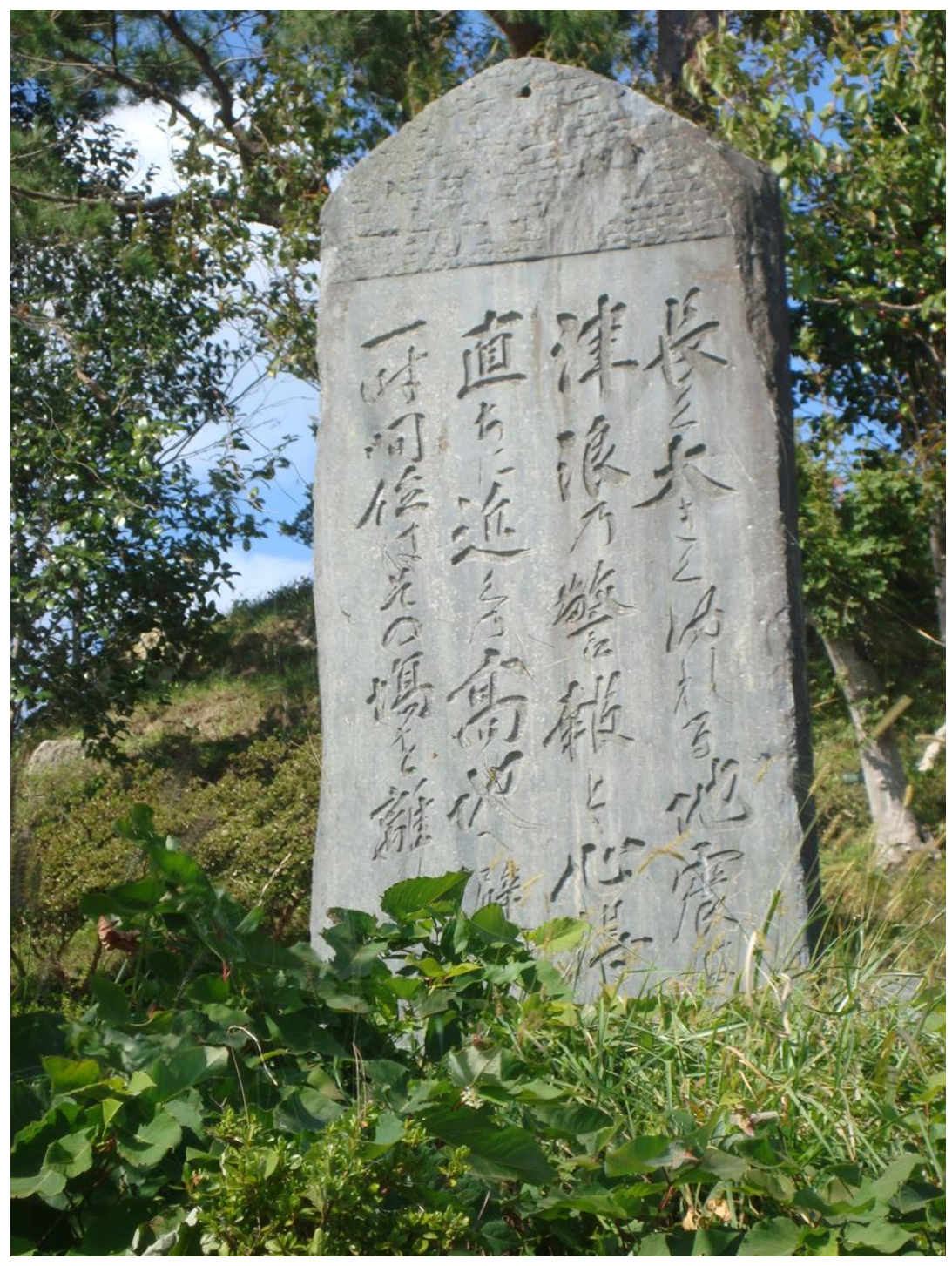


Figure 1. A stone monument installed in Ōfunato after the tsunami of 1933. It says "Remember that a big, prolonged quake is the warning for a tsunami. Evacuate immediately to nearest higher ground and stay there at least for an hour" (by Shuhei Kimura)

After a thirty-year interval, another large tsunami - this time coming from the other side of the Earth - reached the coasts in 1960. This tsunami was called the Chilean Earthquake Tsunami, since it had been generated by a big earthquake in the Pacific Ocean near Chile. In Japan, it killed about 140 people. This tsunami was dramatically different from the previous two ones. The wave height in the coastal area was much lower, and because the point of origin was very far away, the waves were so slow that they took half an hour to arrive and half an hour to withdraw. Some survivors told me that people were able to walk on the sea floor and gather fish and clams while the waves were out. Prior to 2011, this was the biggest tsunami in living memory. Consequently it shaped the local image of what a tsunami was like.

After the Chilean Earthquake Tsunami, a large-scale public investment in seawall construction was launched. The seawalls were built in the $1960 \mathrm{~s}$, a period of rapid economic growth. ${ }^{10}$ The protection of the coastline had been on the government agenda prior to the 1960 tsunami, since yearly typhoons were causing a large number of casualties. The Coast Act was enacted in 1956 and the Building Standard for Shore Protection Facilities in 1958. A severe typhoon killed more than 5,000 people in 1959, the year before the Chilean Earthquake Tsunami. Subsequently, the Disaster Basic Law was enacted. Henceforth all towns and villages on the Pacific coastline were to be enclosed by seawalls as part of the national public works project.

It is noteworthy that most of the seawalls constructed in this period were only a few meters high, much lower than those currently under consideration. The reason was that their primary aim was to block high waves caused by typhoons and moderate-height tsunamis like the Chilean Earthquake Tsunami, rather than more dramatic but infrequent events like the tsunamis of 1896 or 1933 . At the time it was said that it would not be feasible to build

10 As mentioned above (in note 4), in 1962, the Japanese central government launched a series of five-year Comprehensive National Development Plans, aimed at developing rural areas through New Deal-like large-scale public works that included the construction of infrastructure such as roads and dams. Although the central government supported this construction-oriented approach at the time, this policy is now considered to have had harmful effects on Japan's administrative system. 
higher seawalls. Moreover, the government did not have reliable data on the heights of these earlier tsunamis. For this reason, the Chilean Earthquake Tsunami established not only the local image of tsunamis but also the official standards for anti-tsunami infrastructure. Fortunately or unfortunately, these low seawalls were exactly the right height to block the tsunami that hit the area in 1968. Along with the discourse formed by the Disaster Basic Law, this success helped to cement the structure-oriented framework of tsunami countermeasures in Japan. Thus, it popularized and strengthened the belief that tsunamis could be mitigated exclusively by means of seawalls. In the 1980s, the seawalls were raised by several meters because of widespread anticipation of the so-called Tokai Earthquake, which experts believed was imminent (though it has not occurred to date). Yet although the experts began emphasizing earthquakes, this did not cause them to revise their general framework for disaster prevention.

I suggest that the seawalls index a shift in the mode of public safety infrastructure from structures supporting evacuation to structures providing protection. While older safety devices such as stone monuments and fukkouchis added to the everyday landscape of local communities, the seawalls enclosed the communities, creating a division between land and sea. Although the seawalls did not obstruct the view of the sea very significantly, they concealed the danger inherent in living in the coastal communities, replacing living memory with 'evidence' of past events. Yet, as noted, despite the lack of sufficient scientific data and, thus, of technical justification for the chosen height of the seawalls, these walls became the basis of a structure-oriented framework of tsunami prevention and a myth of safety. Thus, the anthropologist Ryan Sayre (2013) recalls that, not long before the 2011 disaster, when he asked a disaster preparedness expert about tsunamis, she replied without hesitation that 'Tsunami preparedness is over.... The problem has been overcome.'

\section{Reassessing risk}

The 'thousand-year tsunami' following the Great East Japan Earthquake of 2011 shattered the public myth of safety. It revealed the fragility of Japanese society on a scale reminiscent of Japan's defeat in World War II (Murakami, 2011). Nevertheless, despite the obvious insufficiency of the existing system, the tsunami only served to strengthen the bureaucratic framework underlying Japan's the disaster prevention efforts. In other words, the tsunami did not cause an 'overflow' to the practices and strategies of disaster management (Callon, 1998; Hilgartner, 2007). Reviewing the national tsunami hazard map in the aftermath of the tsunami, the Central Disaster Prevention Council under the Cabinet Office recommended that the government should prepare for another gigantic tsunami, regardless of its low

probability. Based on this recommendation, the government identified two (ambiguously defined) levels of tsunami. 
L1: A tsunami that is destructive yet small enough to have a relatively high likelihood of occurrence. Damage from this kind of tsunami should be prevented through structural protection. The goal is the improvement of structures.

L2: The largest tsunami possible in the area. This kind of tsunami cannot be mitigated through structural protection alone. Thus the goal must be the development of comprehensive, multi-layered measures. ${ }^{11}$

Given the costs and benefits of various possible seawall designs, the government decided to construct the seawalls at a height that would block L1 tsunamis only. Since an L2 tsunami must be expected to run over the seawall, its destruction must be prevented through 'comprehensive, multi-layered measures,' that include structural measures as well as nonstructural measures such as residents' quick reactions.

While local municipalities essentially have the responsibility for reconstruction in each community, at this time the prefectural governments are in charge of the large-scale seawall reconstruction project. Given the ambiguity of the definitions of tsunami type, each prefectural government could interpret them in their own way, and set the heights for the proposed seawalls according to their own standards. In Iwate Prefecture, for example, the expert committee interpreted the description of L1 to mean 'the height of a tsunami that is likely to occur more than once every two hundred years.' They then, rather arbitrarily, divided the coastline of Iwate into 24 units and assessed the heights of past tsunamis within each. Within this system, the main cove of Maehama was placed within the 20th unit together with the cove of a neighboring community, while the other two coves of Maehama were assigned to the 19th unit. The expert committee subsequently defined the exact heights of L1 and L2 tsunamis for each unit based on 'reliable' evidence of past tsunamis. For unit 20, for example, the committee classified the tsunamis of 1896 and 2011 as examples of L2 tsunamis and those of 1933 and 1960 as examples of L1 tsunamis. At the end of the process, they determined the maximum height of an L1 tsunami in unit 20 to be 13.1 meters above sea level.

In the summer of 2011, about six months after the tsunami, the prefectural government presented Maehama with three options for the height of a new seawall for the main cove: 14.1 meters (L1 height for the entire unit plus 1 meter), 8.7 meters (L1 height for the cove plus 1 meter), and 7.9 meters (same height as the existing seawall). The officials did not hide their preference for the highest wall. To my surprise, few locals objected explicitly to

11 Although the government published its English version, I translate these sentences by myself to convey the feel of the original Japanese text. 
this preference, which would double the height of the existing wall. Perhaps this was because most people welcomed a radical reform of the disaster management system so soon after the disaster. At that time, they may not have truly comprehended the long-term effects of this decision on their daily lives. As I discuss below, a negative view of the tall seawall only gradually emerged.

\section{Another project: marking the border}

Apart from the discussion over seawalls, alternative responses to the devastation have also appeared gradually. These responses have taken the form of structures that alter the landscape of the affected communities in order to remind residents of the risk of tsunamis. In Rikuzen Takata, for example, a town just south of Ōfunato, a newly-organized non-profit organization named 'Sakura Line 311' has launched a project to plant sakura (cherry trees) at ten meter intervals along the border of the flooded area for the entire length of the town. As is well known, cherry blossoms are central Japanese symbol, and people gather under the cherry trees when they blossom in the spring. The founder of Sakura Line 311, a young man who grew up in Rikuzen Takata and returned to live there in the aftermath of the tsunami, told me that his vision is for people to remember the tsunami when the cherry blossoms bloom. At the same time, this makes the borderline of high water easily visible. Moreover, he hopes that the line of trees will help future generations understand the vast destruction of March 11 tsunami, and that they will offer a guide for evacuation in the case of the next tsunami.

Another example is from a small hamlet in Maehama. During a visit to this hamlet in support of reconstruction efforts ${ }^{12}$, we suggested to the locals that they build a tsunami memorial. They accepted this idea, choosing to mark the border of the flooded area. With the project installed by Sakura Line 311 in mind, an urban planning colleague of mine advised them to use cherry or camellia trees (the symbol of Ōfunato city) to mark the high water line. The locals, however, believed that a boundary line made of such trees would soon become indistinguishable from the surrounding landscape. Instead, they proposed to use wooden stakes. These one-and-a-half-meter stakes, the head of the hamlet explained, would attract attention by virtue of being artificial in a rural landscape. In economical terms, the stakes are much cheaper than stone because wood is abundant in the mountains near the hamlet. The residents of the hamlet were aware that the stakes would decay within a few decades, but they anticipated that future generations would replace them when they wore out, thus refreshing their memory of the tsunami.

We also proposed that they decorate the stakes, but this suggestion, too, was rejected.

12 See note 1. 
Instead, a minimal amount of information was written on each stake: simply informing readers that the stakes mark the high-water line of the tsunami associated with the Great East Japan Earthquake, and providing the date of the catastrophe. Their repeated rejections of our ideas in favor of their own impressed us: they knew what they needed to add to the landscape to achieve their own purposes.

In contrast with 'the mode of prevention' represented by the seawall, these projects are in line with what I have called 'the mode of evacuation;' a mode that also includes the older stone monuments and fukkachous. In some ways, building higher seawalls and marking the high-water line is in some incongruent, if not opposed. For example, if the force of the next tsunami is weakened by the seawall, the location of the previous high-water line should be less significant. Indeed, given the totally different wave heights of the tsunamis of 1896, 1933, 1960, and 2011, marking the high-water level of one tsunami with great precision is not necessarily very important. But then, the purpose of marking the high-water line of the 2011 tsunami is not primarily to demarcate a guaranteed safety zone. Instead, as the head of Sakura Line 311 said, it merely offers a guide for evacuation.

On closer inspection, the mode of building high seawalls and that of marking the highwater line are opposed on even more fronts. First, while the seawalls represent the predicted vertical height of expected future tsunamis, the boundary markers record past tsunamis planimetrically. Second, while the seawalls divide the land and the sea, the markers are embedded within the original landscape. Third, while the seawalls obstruct the view of the sea, the markers supplement their view, thus allowing them to imagine the potential destruction that a tsunami could cause while also allowing a view of the present natural landscape. Fourth, while the seawalls are gigantic stand-alone structures, the markers are small, numerous, and coordinated. Finally, while the seawalls is likely to be decreasingly noticed as time passes, the boundary markers, whether in the form of trees or stakes, will be more or less visible at various times of the year. My key point, however, is not to simply to contrast these approaches. It is that they are indicative of entirely different disaster mitigation practices and strategies. These practices and strategies reflect different, inconsistent visions not only of the landscape, but also of time, as one mode looks to past experience, while the other is fixed on predicting the future. In other words, they imply different ways of infrastructuring environments for safety information.

As mentioned above, a large proportion of survivors, not only fishermen but also office workers, maintain that a good view of the ocean is a vital part of their community because they have been accustomed to such a view all their lives. Of course seawalls did exist prior to the tsunami of March 11, and although they were much lower than the new walls now being considered, they did partially obstruct the view. Precisely for this reason, immeadiately after the March 11 earthquake, residents of Maehama who wanted to watch 
for a coming tsunami rushed to the fukkouchis.

For the villagers, having a view of the sea thus does not necessarily mean being able to see it from anywhere. Rather, what is needed is certain places in the village from which the sea will always remain visible. Although these claims can be defined in terms of a demand to lower the height of the seawall, the height is not the only issue at stake. The larger issue is how to build better public safety infrastructure, infrastructuring the environment in a way that also allows for the preservation of an organic, everyday relationship with the landscape. Locals are convinced that they can stay in close vicinity of the sea and yet defend themselves from natural disasters inasmuch as this relationship is maintained.

In contrast, officials from the local government consider the height of the proposed seawalls to be non-negotiable. They underline the importance of a long-term perspective in order to prepare for infrequent large tsunamis of the future. To their eyes, the unwillingness of local people to embrace radical infrastructural change speaks only to their shortsightedness.

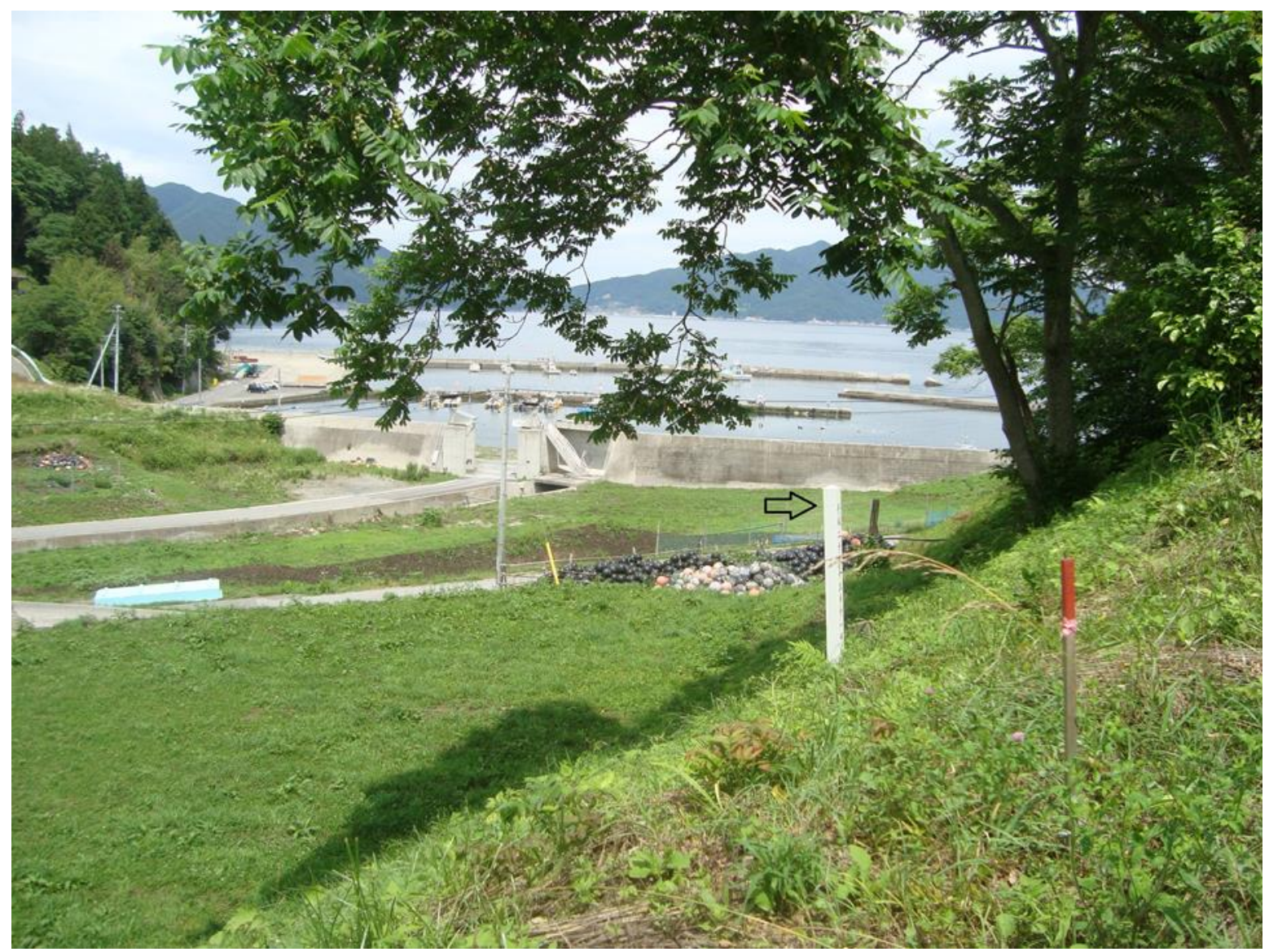


Figure 2. One of ten wooden stakes installed in a small hamlet in Maehama (by Shuhei Kimura)

\section{Toward a visible infrastructure}

In the winter of 2012, the fourteen-meter seawall proposed for Maehama reemerged as a problem. This slow reaction made Maehama in some sense atypical, for some communities were objected to what they saw as the harmful effects of a high seawall during the early stages of planning. Supported by scholars and intellectuals, these communities held study sessions to examine the planned seawall reconstruction projects and issued statements against them. Even so, they have had great difficulty in actually changing the heights of the planned seawalls. In general terms, they are blocked by Japan's compartmentalized and rigid hierarchical administrative structure. According to this structure, a local municipality complies with the official policies and implicit instructions of the prefectural government, and the prefectural government complies with those of the central government.

Within this bureaucratic hierarchy, each level internalizes the authority and oversight of the levels above, and the lowest levels are expected to adhere most rigidly to rules and regulations. Although the central government frequently communicates its openness to flexible interpretations of the rules, in practice officials from local municipalities are thus very reluctant to deliver local opinions and requests to the prefectural government. One level up, officials from the prefectural government are similarly reluctant to report prefectural concerns to the national government. It thus quite convenient for officials to hide behind a uniform 'scientific' standard and decline the diverse requests from local communities in the name of fairness.

In this context, it would therefore be most helpful to local citizens if different opinions could be more easily accommodated within the government-led reconstruction project. That would entail creating a possibility for individual villages' requests for lower seawalls to be presented to bureaucrats at each level, not only the lowest one. Retelling Maehama's struggle not to lower the seawall but rather to build a more visible form of infrastructure, I explore one possible way to deal with this challenge.

In the winter of 2012, we participated in the drafting process for the village's reconstruction plan. Based on interviews with a variety of Maehama residents, my urban planning colleagues proposed a new land-use plan for the central area of the village. It included a planned park and a tsunami-prevention forest in the area adjacent to the central cove. Since this area had been flooded by the tsunami of March 11, we expected that the local municipality would regulate land use in this area. By prohibiting residents from rebuilding houses there, the municipality would open the area for use as a park and a forest, something imagined to help revitalize community life in Maehama. 
Unexpectedly, however, the municipality declared that it would not prohibit the building of homes throughout the formerly flooded area. In accordance with guidelines, they determined that land use regulation would be implemented only in areas that they predicted would be inundated with more than two meters of water in a future L2 tsunami. This prediction, and thus the size and shape of the areas where home building would be prohibited, depended heavily on the predicted success of the proposed higher seawalls. Put simply, the higher the seawalls, the smaller the predicted flood area. Along with the core members of the residents' association, we were perplexed. In the absence of effective land use regulation, our plan to rebuild a safer village would never work. It seemed likely that, even if locals who had survived the 2011 tsunami declined to rebuild their houses in the formerly flooded area, over the years newcomers and younger generations would come to disregard the history of the area. It might well be full of new buildings within a few decades. In sum, the municipality's decision not to regulate land use would invite another round of soutei-gai.

Here, the seawalls 'became visible' once more as local expectations broke down. Since the village's future now depending entirely on these walls, people started to come to terms with their actual projected size. Moreover, they realized, the construction plan presented by the municipality had no gate in the seawall. Officials from the municipality said that a gateless wall was chosen to reduce both risk and cost. However, the absence of a gate also meant that local people would have to climb over the seawall to access the port and the fishery. This would be inconvenient for fishermen trying to conduct their daily business, and would require a large area of private property to be set aside so that a slope gentle enough to climb could be built.

Using his laptop, one of my urban planning colleagues generated a few images of what the planned seawall would look like once it was in place. These images made it clear to the locals that the seawall would cause many problems. Aside from the inconvenience to local fishermen, it made visible that the seawall would cover an important shrine on the tip of the cape enclosing the cove. Paradoxically, it would also put the fukkouchis at greater risk. From the time of their construction after the tsunami of 1933, the fukkouchis have not suffered any damage due to subsequent tsunamis. However, if the new seawalls were built higher than the fukkouchis, and a future tsunami were to overflow the seawalls, these areas would not be able to survive undamaged. People objected to the idea that the shrine should be disturbed or dismantled, and to the possibility that the fukkouchis might be flooded.

As people started to imagine the planned seawall in the context of the preexisting elements of the landscape, they became better able to imagine the problems the wall would likely cause. This restarted the debate, which became increasingly complicated as it began to show divisions in the village, with residents taking sides according to their neighborhoods, 
occupations, ages, and so on. This back-and-forth continued for months. Finally, in the spring of 2013, the residents' association submitted a request to the municipality for a 12meter seawall, which would not cover the shrine or the fukkouchis, but which would preserve the existing places in town with clear views of the sea. Interestingly, whether knowingly or not, they chose a height that would allow them to see the village from the sea as well.

Our group contributed to the negotiations with the local municipality and the prefectural government. Not surprisingly, the local municipality and prefectural government hesitated to accept the request. Negotiations stalled for months. Suddenly, in the summer of 2013, the municipality came up with a brand new option of 11.6 meters, claiming that the calculations on which they had based their former recommendation of 14 meters had been incorrect. To be honest, we were amazed. Though we were not sure if a miscalculation had really occurred, we decided not to investigate the true reason for the changed recommendation. Regardless, the height of the proposed seawall now conformed to the local request. Like '14.1', '11.6' is just a number, yet both local people and the municipality gave these numbers powerful meanings.

At this point I want to draw your attention to two things about this story. First is the way in which the vision and visualization of the local people entered into the negotiations. With help from urban planners, the disadvantages of the planned seawall became visible. Visually integrating the planned seawall into the existing landscape enabled the villagers to see the need for an alternative proposal. In other words, the planners provided a virtual infrastructure that enabled local people to examine the planned infrastructure more realistically and more seriously. Second is the fact that this seemingly easy victory was actually only a temporary settlement that permitted the reconstruction process to move forward (cf. Kimura, 2015). Although the local people's request was apparently straightforward -- simply a matter of lowering the height -- it actually reflected an assortment of opinions. Many things remain to be discussed, both among the villagers and between the villagers and the municipality. These topics include the details of the architecture of the seawall and the establishment of an organization to manage the proposed park and forest. Thus far, in any case, the most significant progress has been made through 'continually seeking new connections' (Fortun, 2001: 5-6). Through their efforts to visualize the seawall as it relates to the landscape, locals have been able to maintain their commitment to the seawall, while also striving to keep it in a form that will be locally meaningful.

In the spring of 2015, Konno-san and his two children moved out of their temporary housing. Their new home is a public apartment house for tsunami-afflicted families. In this brand-new four-story building, they are beginning their lives again. In Maehama, new monuments have been installed, a forest on higher ground has been cleared and the land 
developed into a new fukkouchi. The fishing ports are back in a shape similar to the time prior to the 2011 tsunami. However slowly, the process of recovery advances as people gradually add new elements to their lives and their landscapes.

\section{Concluding remarks}

In this paper I have narrated the story of one small village's complex responses to the prospect of seawall reconstruction. Prior to the tsunami, the existing seawall, an outcome of the government's structure-centric approach to disaster management, was an unnoticed element of the coastal landscape. However, tsunami created 'overflow,' making the seawall 'visible upon breakdown.' The response of the government was to propose the building of even larger structures. Meant to protect the communities, these walls were meant to slowly become unremarkable, fading into the background of community life. They would also make the sea itself invisible. Meanwhile, the local community also developed reconstruction plans for the area. In contrast to government plans, these focused on marking the boundaries of the high-water line with trees or stakes. These elements were specifically meant to remain visible, keeping the memory of the dimensions of the tsunami alive.

These strategies for infrastructuring the environment with a view to mitigating the risk of future catastrophe vary not least because of their different assumptions about infrastructure itself. Whereas the government solution is based on a quantitative and technical understanding of infrastructure, and therefore zooms in on the height of the solutions as the key parameter, local discussions emphasize numerous other aspects. In particular, they introduce into their considerations qualitative dimensions, including whether it will be possible to see the sea and other landmarks, such as shrines, whether high areas will suffer increased risk, and whether it will be possible to remember the catastrophe.

Here I have explored these contrasting perspectives on safety infrastructure with a specific view to what they teach about the relation between infrastructure, visibility and invisibility. The governmental seawall solution lives up to the conventional idea of infrastructure as large (in that sense visible) structures that are nevertheless meant to operate silently in the background (and in that sense become unremarkable). However, the wall would make other things unremarkable too. It creates a scenario of fading memory, since it poses no obligations for people to remember previous events and tragedies. And it renders the sea itself invisible, with negative consequences for every day lives and for evacuation in the face of a new disaster. In contrast the commemorative markers operate by keeping infrastructure visible, memorable and thus remarkable.

As the case also suggests, however, there is not necessarily a total opposition between these approaches to infrastructuring the environment for safety. Over time, a

solution was negotiated in which boundary markers would complement a lowered wall, in 
a way that would, so to speak, mix the visibilities. This demonstrates that ongoing efforts to maintain the relation of communities with their infrastructures can help keep it visible and remarkable. This unfolding situation is indicative of an intricate and transformable, rather than binary and static, relation between the visibility and invisibility of infrastructure.

In the case of Maehama, the proposed new seawall became visible to local people when the urban planners placed its image in a virtual landscape. Presented with a virtual image of the real landscape, local people realized that the proposed seawall was much higher than they had expected. As this shows, the seawall is not the only infrastructure of consequence in this story. The segmentation of the coastline generated 'scientific' evidence about the environment for the government. And the urban planner's virtual image facilitated the local people's reaction.

Finally, implied by their commitment to preserving a view of the sea, the local landscape as a whole is also a form of infrastructure for people's everyday lives. These interrelated infrastructures in Maehama underpin the delicately negotiated temporal shifts between visibility and invisibility, which have held my attention in this paper.

After a disaster like the 2011 tsunami, a student of science and technology must remain committed to improving the lives of the survivors. Here I have suggested that this entails paying close attention to dynamic transformation of infrastructure, which seems able to continuously incorporating new elements - from higher seawalls to cherry blossoms. The ultimate aim, however, is to enable people to move forward after the disaster.

\section{References}

Akasaka, N., Oguma, E., and Yamauchi, A. (2011) Tohoku Saisei (Rebirth of Tohoku), (Tokyo: East Press).

Anand, N. (2011) Pressure: the politechnics of water supply in Mumbai, Cultural Anthropology, 26(4), pp. 542-564.

Bowker, G. and Star, S. L. (1999) Sorting Things Out: Classification and Its Consequences (Cambridge: The MIT Press).

Callon, M. (1998) An essay on framing and overflowing: economic externalities revisited by sociology, in: M. Callon (Ed) The Laws of the Markets, pp. 244-269 (Oxford: Blackwell Publishers).

Collier, S. J., and Lakoff, A. (2008) Distributed preparedness: the spatial logic of domestic security in the United States, Environment and Planning D: Society and Space, 26(1), pp. 7-28.

Dalakoglou, D. (2010) The road: An ethnography of the Albanian-Greek cross-border motorway, American Ethnologist, 37(1), pp. 132-149. 
Deleuze, G. (1992) Postscript on the Societies of Control, October, 59, pp. 3-7.

Edwards, P. N., Bowker, G. C., Jackson, S. J., and Williams, R. (2009), Introduction: an agenda for infrastructure studies, Journal of the Association for Information Systems, 10(5), pp. 364-74.

Elyachar, J. (2010) Phatic labor, infrastructure, and the question of empowerment in Cairo, American Ethnologist, 37(3), pp. 452-464.

Fortun, K. (2001) Advocacy after Bhopal: Environmentalism, Disaster, New Global Orders (Chicago: The University of Chicago Press).

Foucault, M. (2009) Security, Territory, Population: Lectures at the Collège de France, 1977-1978 (New York: Palgrave Macmillan).

Giddens, A. (1991) Modernity and Self-Identity: Self and Society in the Late Modern Age (Stanford: Stanford University Press).

Hilgartner, S. (2007) Overflow and Containment in the Aftermath of Disaster, Social Studies of Science 37(1), pp. 153-158.

Iwate-ken Doboku-ka (1935) Shinrou Saigai Doboku Shi (Civil Engineering Report on Earthquake and Tsunami) (Iwate: Iwate Prefecture).

Jensen, C. B. (2014) Pipe dreams: infrastructures and infra-reflexivity in Phnom Penh. Paper presented at the workshop on Reflexivity/ Recursivity/ Self-Referentiality, January $11^{\text {th }}$, 2014, Hitotsubashi University.

Kawashima, S. (2012) Tsunami no Machi ni Ikite (Living in a town of tsunami) (Tokyo: Fuzanbo International).

Kimura, S. (2014) Roads, in: D. Naito, R. Sayre, H. Swanson, S. Takahashi (Eds) To See Once More the Stars: Living in a Post-Fukushima World, pp. 28-30 (Santa Cruz: New Pacific Press).

Kimura, S. (2015) Visualizing with "soft light": a reflection on public anthropology and 3/11, Japanese Review of Cultural Anthropology, 15: 127-140.

Lakoff, A. (2008) The generic biothreat, or, how we became unprepared, Cultural Anthropology, 23(3), pp. 399-428.

Larkin, B. (2013) The politics and poetics of infrastructure, Annual Review of Anthropology 42, pp. 327-343.

Morita, A., Blok, A. and Kimura, S. (2013) Environmental infrastructures of emergency: the formation of a civic radiation monitoring map during the Fukushima Disaster, in: R. Hindmarsh (Ed) Nuclear Disaster at Fukushima Daiichi: Social, Political and Environmental Issues, pp. 78-96 (New York: Routledge).

Murakami, H. (2011) As an unrealistic dreamer. Speech delivered for the 23rd Catalonia International Prize.

Numazaki, I. (2012) Too wide, too big, too complicated to comprehend: a personal 
reflection on the disaster that started on March 11, 2011, Asian Anthropology, 11, pp. 27-38.

Samimian-Darash, L. (2009) A pre-event configuration for biological threats: preparedness and the constitution of biosecurity events, American Ethnologist, 36(3), pp. 478-491.

Sayre, R. (2011) The un-thought of preparedness: concealment of disaster preparedness in Tokyo's everyday, Anthropology and Humanism, 36(2), pp.215-224.

Sayre, R. (2013) The externalizing of vigilance and architectural security in Japan. Paper presented at the $112^{\text {th }}$ annual meeting of the American Anthropological Association, November $24^{\text {th }}, 2013$, Chicago.

Star, S. L. (1999) The ethnography of infrastructure, American Behavioral Scientist, 43, pp. 377-391.

Star, S. L. and Ruhleder, K. (1996) Steps toward an Ecology of Infrastructure: Design and Access for Large Information Spaces, Information Systems Research 7, pp. 111-134.

Stavrianakis, A., Fearnley, L, Bennett, G., and Rabinow, P. (2011) Safety, security, preparedness: an orientation to biosecurity today, Berkeley Human Practices Lab. http://anthropos-lab.net/wp/publications/2011/05/safety-security-preparedness-greenpaper-may-2011.pdf

Takahashi, S. (2011) Fourfold disaster: renovation and restoration in post-tsunami coastal Japan, Anthropology News, 52(7), pp. 5 and 11.

Thévenot, L. (2002) Which road to follow?: the moral complexity of an "equipped" humanity, in: J. Law and A. Mol (Eds) Complexities: Social Studies of Knowledge Practice, pp. 53-87 (Durham: Duke University Press). 